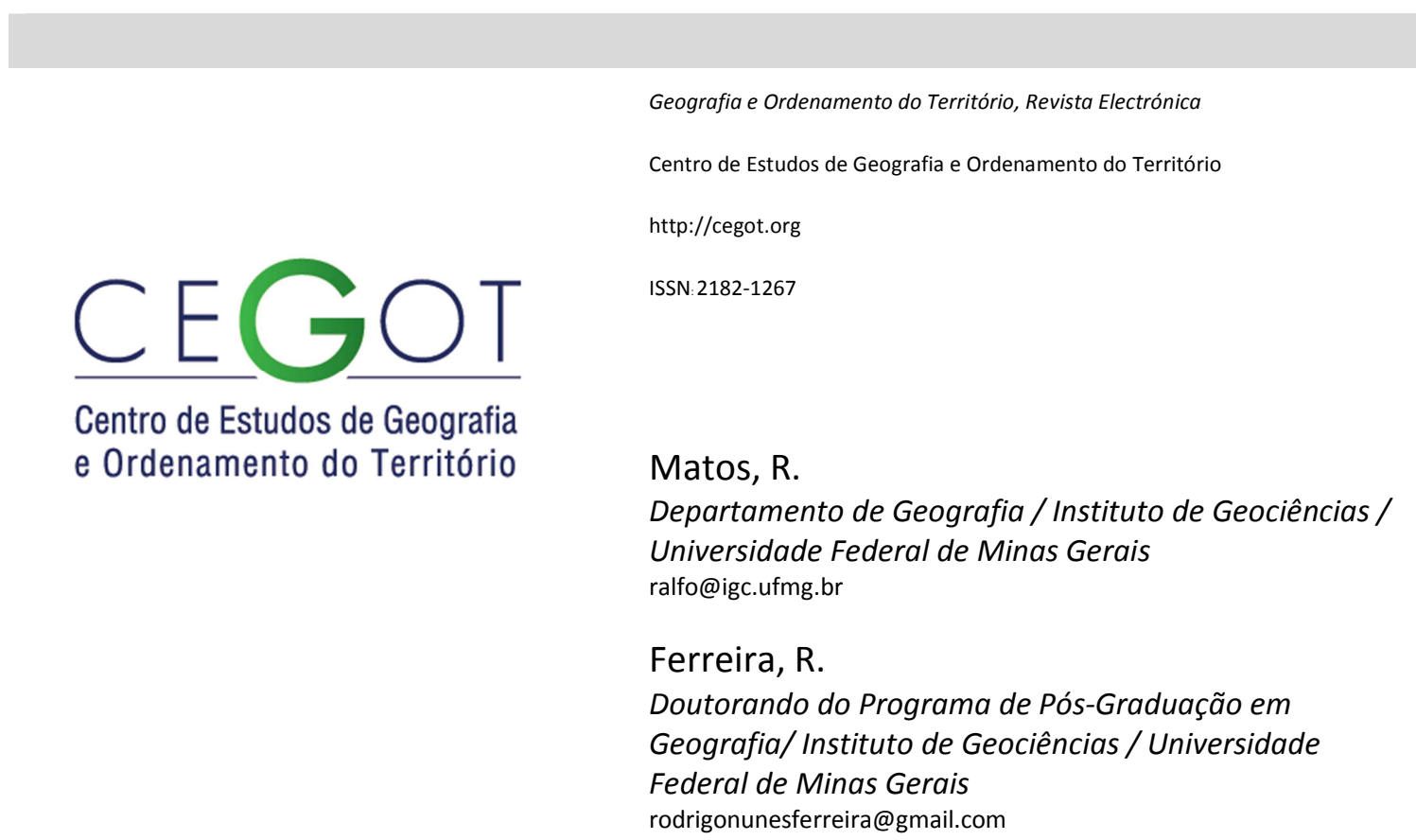

\title{
Setores de atividade, emprego e renda nos municípios brasileiros estratificados por classe de tamanho entre 2000 e 2010
}

Referência: Matos, R. e Ferreira, R. (2014). Setores de atividade, emprego e renda nos municípios brasileiros estratificados por classe de tamanho entre 2000 e 2010. Revista de Geografia e Ordenamento do Território (GOT), n. 6 (dezembro). Centro de Estudos de Geografia e Ordenamento do Território, p. 179-199

\section{Resumo}

Neste artigo examinam-se algumas mudanças na estrutura espacial do emprego no Brasil a partir de dados demográficos dos dois últimos censos. As análises baseiam-se na configuração da rede urbana, mediante informações desagregadas por classes de tamanho dos municípios brasileiros. Os resultados evidenciam que as cidades de porte médio sedimentaram tendências anteriormente observadas: são protagonistas de grande peso no processo de interiorização da urbanização, chegando a disseminar efeitos na estrutura espacial do emprego na rede de cidades. O crescimento do setor de serviços urbanos e as mudanças na configuração das rendas do trabalho principal de homens e mulheres são aspectos particularmente explorados nas análises.

Palavras-Chave: mercado de trabalho; renda do trabalho; desigualdade; rede urbana. 


\begin{abstract}
The article examines some changes in the spatial structure of employment in Brazil, from demographic data from the last two censuses. The analysis is based on the configuration of the urban network by information disaggregated by size classes of municipalities. The results show that medium-sized cities sedimented trends previously observed: the protagonists are of great weight in the internalization process of urbanization, the spread reaching effects on the spatial structure of employment in the city network. The growth of the urban services sector and changes in the configuration of the main incomes of working men and women are particularly aspects explored in the analysis.
\end{abstract}

Keywords: labor market; labor income; inequality; urban network.

\title{
1. Introdução
}

Mudanças na distribuição das atividades, emprego e renda podem ser cotejadas com o processo de interiorização da urbanização no Brasil contemporâneo. São vários os estudos sobre o aumento do emprego formal no país nos últimos 10 a 15 anos, embora poucos associem esse aumento aos processos de desconcentração demográfica e econômica que o país experimenta nos últimos 30 anos. $^{1}$

A urbanização brasileira, em pouco mais de três décadas, trouxe um avanço expressivo das atividades do terciário e isso refletiu no padrão de consumo e no aparecimento de novos estilos de vida, mais afeitos às sociedades de consumo de massa. Essas mudanças são similares às que modificaram a correlação de forças políticas que beneficiara por séculos velhas oligarquias rurais do passado.

Nesse processo, a socioeconomia ganhou novas tessituras e o tamanho do Estado aumentou e diminuiu. Mas hoje, mesmo após a onda de privatizações do período 19942002, a máquina pública é de grande tamanho e o Estado continua sendo um fator determinante, capaz de gerar incentivos (ou desincentivos) econômicos, boa parte deles associados ao incremento da interiorização da urbanização brasileira.

Paralelamente, aspectos sociais e territoriais - país de ecúmeno extenso e com histórico de populações migrantes sem acesso a terra - perpassam as evidências de dispersão de milhões de pessoas pelo interior da rede de cidades, vis-à-vis a intensa modernização da

\footnotetext{
${ }^{1}$ A despeito da existência dos céticos que analisam a conjuntura econômica do país ignorando a expansão da rede urbana brasileira e seus efeitos sobre a economia nacional.
} 
sociedade brasileira a partir de 1980. O avanço da transição urbana juntamente com a progressão da transição demográfica fez declinar as taxas de crescimento da população; muitas regiões e cidades aumentaram seu peso demográfico à custa de fluxos migratórios não mais de tipo campo-cidade, mas principalmente causados por movimentos migratórios entre cidades de uma rede urbana crescentemente mais densa. Novos polos urbanos emergiram apoiados por redes de transporte e de circulação e por investimentos setoriais, boa parte deles derivados da presença de empresas e órgãos do Estado. Esses movimentos contribuíram para expandir significativamente os serviços do alto e do baixo terciário em muitos centros urbanos não metropolitanos. As próprias regiões metropolitanas, que viveram processos explosivos de crescimento econômico-demográficos, participaram dos movimentos centrífugos, porquanto muitos dos novos moradores das cidades médias são migrantes procedentes de áreas metropolitanas.

A despeito da existência de questões não negligenciáveis de teoria econômica que discutem crescimento e desenvolvimento, parte delas ancoradas no paradigma cepalino, o fato é que o país viveu por décadas uma vigorosa expansão industrial, sucedida pelo incremento do setor de serviços não necessariamente nos moldes canônicos de teses como as de Kaldor (1966). Acrescente-se que a desindustrialização não é uma evidência posta à prova no Brasil atual. Não há um processo de desindustrialização em curso. Os dados de emprego formal da CAGED mostram que o estoque de mão de obra atraído pela indústria de transformação perdeu participação para o setor terciário. Entretanto, "a análise intraindustrial mostrou que os setores classificados como de alta intensidade mantiveram suas participações no emprego total" (SQUEFF. 2012, p. 49).

A despeito das considerações de Pochmann (2012), é bem provável que algumas controvérsias sobre a nova classe média brasileira só ganhem mais clareza quando se levar em conta o rol de mudanças econômicas de largo alcance espacial que impactaram a sociedade urbano-industrial que o país viu aflorar nos últimos 50 anos. $^{2}$

\footnotetext{
2 Pesquisa do IPEA, intitulada "Pobreza e Riqueza no Brasil Metropolitano", coordenada por Márcio Pochmann, revelou que nas seis principais regiões metropolitanas do país mais de três milhões de indivíduos haviam deixado de ser pobres entre 2002 e 2006, o que correspondia a uma significativa queda de 8,8 pontos percentuais na taxa de pobreza - que chegava a $24,1 \%$.
} 
De outra parte, a Constituição de 1988, com o passar do tempo repercutiu na dinâmica social e econômica do Brasil atual: influiu na trajetória de parte da economia real, revigorou a vida de relações em cidades e regiões e fortaleceu um leque de ações do Estado (na linha dos teóricos do statecrafting). Uma série de iniciativas governamentais e não governamentais retoma, sob novas perspectivas, a questão do desenvolvimento econômico e planejamento territorial, a despeito da falta de clareza sobre como construir um projeto nacional bem pactuado.

Enfim, a interiorização da urbanização é tema instigante e permite a exploração de dados regionalizados de emprego e renda, como os disponibilizados pela Relação Anual de Informações Sociais (RAIS). Alguns estudos publicados nos últimos 15 anos tratam da redistribuição do emprego por cidades médias dinâmicas, a maioria deles no setor de serviços, tais como Matos (2000), Matos e Braga (2002), Matos e Ferreira (2004, 2005, 2013), Ferreira e Matos $(2005,2010)^{3}$. Esses trabalhos identificam mudanças no mercado de trabalho do Brasil não metropolitano que acabam por beneficiar milhões de pessoas da rede de cidades.

\section{Metodologia}

O presente artigo dá prosseguimento às análises supracitadas quando examina algumas mudanças na estrutura espacial do emprego no Brasil recente com base em dados demográficos dos dois últimos censos. As análises procuram visualizar essas mudanças na rede urbana representada por meio de quatro classes de tamanho dos municípios: i) até 50.000 habitantes; ii) de 50.000 a 500.000 habitantes; iii) de 500.000 a 1.000 .000 habitantes; iv) mais de 1.000 .000 de habitantes). ${ }^{4}$

\footnotetext{
${ }^{3} \mathrm{Na}$ atualidade poucos discordam da relevância da dispersão do emprego no país. Jornais de São Paulo notificam esse fato como se fosse um fato inaudito. Concluem que melhorou substancialmente a condição social da população em razão do maior acesso a uma série de bens de consumo. Renato Meirelles, do Data Popular declarou ao Estado de São Paulo que houve uma forte redução do contingente de pobres e declínio das participações das classes E e D na estrutura social. Nossos estudos expõem tendências como essas, com base em dados do Censo e da RAIS, desde meados da década passada.

${ }^{4}$ Nesse artigo a classe dos municípios com população entre 50 e 500 mil habitantes será indistintamente denominada de "grupo dos municípios intermediários", "classe dos municípios de porte médio", "classe dos municípios de cidades médias", ou eventualmente "grupo das cidades médias".
} 
A estratificação da população que auferiu renda do trabalho nos Censos de 2000 e 2010 por classes de rendimentos corrigidos pelo INPC (Índice Nacional de Preços ao Consumidor) deixa evidente que os municípios de porte médio (com população entre 50 e 500 mil habitantes) sedimentaram tendências observadas nos últimos 20 anos: são protagonistas de grande peso no processo de interiorização da urbanização, chegando a disseminar efeitos na estrutura espacial do emprego na rede de cidades. Essa leitura é resultante de dados de variação dos rendimentos de trabalho no período 2000-2010 acima da média nacional, como visto nas conclusões de Matos, Ferreira e Garcia (2013): a expansão do emprego nas cidades médias é uma evidência verificável nos dois últimos censos e as diferenças em termos de qualidade de vida com as metrópoles praticamente desaparecem. Nas cidades médias, apesar da inferioridade em termos de infraestrutura básica e dos reflexos variáveis das desigualdades regionais há menos constrangimentos socioespaciais, os quais resultam em ganhos de renda e de qualidade de vida.

De todo o modo, as análises ainda devem rastrear outras dimensões da geografia econômica atual, de modo a mapear os setores de atividade que participam mais explicitamente do incremento dos rendimentos do trabalho em áreas urbanas de alta centralidade na rede de cidades. Cabe indagar se, afinal, é o setor terciário quem mais emprega e dinamiza os polos não metropolitanos, ou se a agricultura, a indústria e a agroindústria são os setores mais decisivos na reconfiguração desses espaços econômicos. Assim, tanto o crescimento do setor de serviços - do alto e baixo terciário - e suas correlações com a expansão da agricultura e indústria são temas examinados e discutidos no artigo, a despeito de o foco das análises fixar-se nas mudanças na configuração das rendas do trabalho no terciário urbano. ${ }^{5}$

\section{Resultados}

\subsection{Pessoal ocupado por setores de atividade}

No início do século XXI, entre os anos 2000 e 2010, as comparações entre o crescimento da população e da renda trazem resultados que sinalizam para um contexto de prosperidade

\footnotetext{
${ }^{5}$ Acrescente-se que o debate sobre localização e características da chamada nova classe média brasileira está longe de se esgotar e pode associar-se ao mesmo processo de interiorização da urbanização aqui discutido.
} 
econômica. O rendimento total da população empregada com 15 ou mais anos de idade cresceu $3,9 \%$ ao ano, três vezes mais que o crescimento da população total (1,2\% a.a.). Se a comparação for feita com a população empregada de 15 ou mais anos de idade, o que soa mais condizente, ainda assim a renda cresceu bem mais que o estoque de pessoas empregadas entre 2000 e 2010.

E se excluirmos as rendas individuais não derivadas do trabalho nessas comparações o que os dados nos dizem? Além de mostrarem que a renda do trabalho principal é a mais importante entre as demais rendas, deixa evidente que a população de referência (15 anos e mais) teve sua renda aumentada pelo trabalho principal em $3,4 \%$ a.a., bem mais que os 2,8\% a.a., número que ainda expressa um crescimento de uma população ativa herdeira de épocas de níveis mais altos de fecundidade.

Como esse estudo procura sondar diferenciais socioeconômicos na rede de cidades do país, utiliza-se o conhecido mecanismo de estratificar as localidades de acordo com diferentes classes de tamanho dos municípios (todo município possui uma cidade segundo legislação do IBGE ainda vigente) como observado na introdução. Tendo em conta que na atualidade quanto mais populoso é o município maior é o seu grau de urbanização, o que nos dizem as comparações das taxas de crescimento demográfico e da renda individual?

Em primeiro lugar, os municípios que reúnem a maioria das cidades de porte médio do país (entre 50 e 500 mil habitantes) são os mais dinâmicos porque experimentaram o maior crescimento da renda total e da renda do trabalho principal ( $4,3 \%$ a.a. e $3,9 \%$ a.a.) e os maiores crescimentos da população empregada com 15 anos ou mais de idade $(3,4 \%$ a.a. contra $1,5 \%$ a.a. da população total dessa classe de tamanho).

Curiosamente, à medida que diminui o tamanho dos municípios maior foi o crescimento do rendimento da população ativa. Isso deve se explicar pela disparidade da base de comparação estatística: até muito recentemente os municípios de pequeno porte estavam desprovidos de oportunidades de trabalho e negócios o que teria começado a alterar-se nos últimos decênios.

Os dados da Tabela 1 também apontam declínio da participação relativa das grandes cidades na população total e na população empregada do país, decorrente de taxas de crescimento inferiores às médias nacionais. Além disso, somente no grupo de municípios de 
1 milhão ou mais de habitantes a população empregada com 15 ou mais anos de idade cresceu a uma taxa superior à taxa de crescimento do rendimento do trabalho principal, $2,8 \%$ a.a. contra $2,7 \%$ a.a., respectivamente. A maior oferta de mão de obra estaria deprimindo os salários? Ou há um gargalo entre trabalho pouco qualificado e oferta de emprego em setores de também baixos requerimentos de qualificação? É provável que ambas as situações sejam encontradas nas metrópoles.

Adicionalmente, uma conclusão que já deve ser assinalada diz respeito à diferença entre as taxas de crescimento da renda total e da renda do trabalho principal (nas grandes cidades esse número é a diferença entre $3,5 \%$ e $2,7 \%$ ). Ou no período muita gente possuía mais de um emprego ou, o que é mais provável, a concentração de renda nas grandes cidades é maior por rendimentos originários de ganhos financeiros, alugueis, heranças etc.

Discriminando os dados dessa tabela de modo a que os principais setores de atividade sejam visualizados, pode-se responder a uma das indagações desse trabalho a propósito da existência de uma conexão entre a interiorização da urbanização e a expansão do setor terciário. Afinal, o processo de interiorização será muito mais consistente se for acompanhado pela expansão significativa do setor de serviços (inclusive o comércio) conforme sugerem alguns clássicos da literatura de geografia urbana. Para tanto, convém organizar os dados como se apresentam na Tabela 2, excluindo as "atividades mal definidas". Registre-se que a ordem de grandeza aqui examinada refere-se à 63.662.727 pessoas ocupadas no ano 2000 e 80.071 .087 ocupados no ano 2010, o que significa um incremento de mais de 16,4 milhões de postos de trabalho, população superior à de muitos países. 
Tabela 1 - Taxas de crescimento anual (\%) da população total, da população ocupada com 15 ou mais anos de idade, da renda total da população empregada e do rendimento do trabalho principal dos com 15 ou mais anos de idade entre 2000 e 2010

\begin{tabular}{|c|c|c|c|c|c|}
\hline \multirow{2}{*}{$\begin{array}{l}\text { Discriminação do crescimento anual de } \\
\text { população e renda }\end{array}$} & \multicolumn{5}{|c|}{ Municípios agrupados por Classes de Tamanho } \\
\hline & $\begin{array}{l}50 \text { mil } \\
\text { ou } \\
\text { menos }\end{array}$ & $\begin{array}{c}50 \mathrm{a} \\
500 \\
\mathrm{mil}\end{array}$ & $\begin{array}{c}500 \text { mil } \\
\text { a } 1 \\
\text { milhão }\end{array}$ & $\begin{array}{c}1 \\
\text { milhão } \\
\text { ou } \\
\text { mais }\end{array}$ & Total \\
\hline Crescimento da população total & 0,9 & 1,5 & 1,2 & 1,0 & 1,2 \\
\hline $\begin{array}{l}\text { Crescimento da população empregada } \\
\text { com } 15 \text { anos ou mais }\end{array}$ & 2,2 & 3,4 & 3,2 & 2,8 & 2,8 \\
\hline $\begin{array}{l}\text { Crescimento da renda total da população } \\
\text { Empregada com } 15 \text { anos ou mais }\end{array}$ & 4,1 & 4,3 & 4,0 & 3,5 & 3,9 \\
\hline $\begin{array}{l}\text { Crescimento do rendimento no trabalho } \\
\text { principal dos empregados com } 15 \text { anos ou } \\
\text { mais }\end{array}$ & 3,5 & 3,9 & 3,4 & 2,7 & 3,4 \\
\hline
\end{tabular}

Fonte: IBGE, Censos Demográficos - Dados trabalhados pelos autores

Tabela 2 - Total de ocupados com 15 ou mais anos de idade por setor de atividade, classe de tamanho dos municípios, participação e variação relativa (exclusive ocupações mal definidas)

\begin{tabular}{|c|c|c|c|c|c|c|}
\hline \multicolumn{2}{|c|}{$\begin{array}{l}\text { Classe de Tamanho dos } \\
\text { Municipios e Variação }\end{array}$} & $\begin{array}{l}\text { Agro- } \\
\text { pecuário }\end{array}$ & $\begin{array}{c}\text { Indústria de } \\
\text { Transformação/ } \\
\text { Extração }\end{array}$ & $\begin{array}{l}\text { Construção } \\
\text { Civil }\end{array}$ & $\begin{array}{c}\text { Terciánio } \\
\text { (Comércio e } \\
\text { Serviços) }\end{array}$ & Total \\
\hline \multirow{5}{*}{$\begin{array}{c}50 \text { mil } \\
\text { ou menos }\end{array}$} & 2.000 & 8.906 .178 & 2.322 .029 & 1.239 .914 & 8.881 .582 & 21.349 .702 \\
\hline & Participação (\%) & 41,7 & 10,9 & 5,8 & 41,6 & 100,0 \\
\hline & 2.010 & 8.931 .638 & 3.024 .376 & 1.775 .437 & 11.867 .387 & 25.598 .838 \\
\hline & Participação (\%) & 34,9 & 11,8 & 6,9 & 46,4 & 100,0 \\
\hline & Variação \% & 0,3 & 30,2 & 43,2 & 33,6 & 19,9 \\
\hline \multirow[t]{5}{*}{50 a $500 \mathrm{mil}$} & 2.000 & 2.403 .992 & 3.832 .527 & 1.931 .892 & 14.505 .348 & 22.673 .758 \\
\hline & Participação (\%) & 10,6 & 16,9 & 8,5 & 64,0 & 100,0 \\
\hline & 2.010 & 2.582 .497 & 4.687 .066 & 2.719 .490 & 20.039 .603 & 30.028 .656 \\
\hline & Participação (\%) & 8,6 & 15,6 & 9,1 & 66,7 & 100,0 \\
\hline & Variação \% & 7,4 & 22,3 & 40,8 & 38,2 & 32,4 \\
\hline \multirow{5}{*}{$\begin{array}{c}500 \text { mil } \\
\text { a } 1 \text { milhão }\end{array}$} & 2.000 & 108.242 & 833.722 & 428.026 & 3.935 .774 & 5.305 .764 \\
\hline & Participação (\%) & 2,0 & 15,7 & 8,1 & 74,2 & 100,0 \\
\hline & 2.010 & 124.232 & 905.498 & 570.519 & 5.189 .192 & 6.789 .440 \\
\hline & Participação (\%) & 1,8 & 13,3 & 8,4 & 76,4 & 100,0 \\
\hline & Variação \% & 14,8 & 8,6 & 33,3 & 31,8 & 28,0 \\
\hline \multirow{5}{*}{$\begin{array}{l}1 \text { milhão } \\
\text { ou mais }\end{array}$} & 2.000 & 108.562 & 1.908 .873 & 943.942 & 11.372 .125 & 14.333 .502 \\
\hline & Participação (\%) & 0,8 & 13,3 & 6,6 & 79,3 & 100,0 \\
\hline & 2.010 & 137.575 & 1.918 .383 & 1.206 .058 & 14.392 .138 & 17.654 .153 \\
\hline & Participação (\%) & 0,8 & 10,9 & 6,8 & 81,5 & 100,0 \\
\hline & Variação \% & 26,7 & 0,5 & 27,8 & 26,6 & 23,2 \\
\hline
\end{tabular}

Fonte: IBGE, Censos Demográficos - Dados trabalhados pelos autores

A primeira conclusão a ser destacada confirma o avanço do terciário nas classes de menor tamanho de município. De fato, o incremento da participação do terciário foi maior no rol dos pequenos municípios (4,8 pontos percentuais entre 2000 e 2010), sucedido pela 
participação dos municípios de porte médio (aumentaram 2,8 pontos percentuais em relação ao ano 2000) e, por último, entre os maiores municípios, que de 79,3\% em 2000 evoluíram para uma participação de $81,5 \%$ em 2010 . Ressalte-se que o aumento dos postos de trabalho nos municípios intermediários foi o mais expressivo entre as quatro classes de tamanho (variação relativa de $32,4 \%$ ).

Afora a classe dos municípios de menor tamanho, onde é alta a presença das atividades agropecuárias e notória a existência de atividades industriais de processamento de insumos do agro; indústrias de extração mineral, e outras plantas industriais que requisitam muito espaço físico, nas três outras classes de tamanho a indústria de transformação e extração perdeu participação relativa: quanto mais aumenta a classe de tamanho mais perde participação, mesmo mantendo variação relativa positiva $(0,5 \%$ no rol dos grandes municípios).

Contudo, há um ramo industrial cujo comportamento na geração de empregos diferiu dos demais. De fato, a indústria da construção - capaz de gerar significativos efeitos de encadeamento a montante e a jusante do processo produtivo - expandiu vigorosamente entre 2000 e 2010 em todas as classes de tamanho de municípios em termos de participação e de variação relativa. Esse tipo de indústria, pouco modernizada e ainda fortemente intensiva em mão de-obra, ao exibir incrementos na oferta de ocupações da ordem de $27,8 \%$ (nas grandes cidades) e $43,2 \%$ (no rol dos pequenos municípios) deve ser um dos alicerces do processo de interiorização da urbanização. Isso por causa dos variados tipos de empreendimentos imobiliários que o setor incorpora e, por via de consequência, deve estar subsidiando a expansão do próprio terciário e do consumo ${ }^{6}$ familiar em áreas urbanas do interior, uma vez que os números do setor são mais proeminentes nas classes de municípios de menor tamanho.

É digna de nota a expansão relativa da construção civil e do terciário no rol dos municípios das cidades de porte médio, 40,8\% e 38,2\% respectivamente. Essa elevação conjunta é bem

\footnotetext{
${ }^{6}$ A construção civil, ao ocupar grande número de trabalhadores, demanda uma vasta gama de bens e serviços necessários no dia a dia dos canteiros de obra. Após o término das obras, parte expressiva do mobiliário dos prédios habitados é adquirida nos estabelecimentos comerciais e de serviços existentes nas localidades onde são erguidas as edificações. Note-se que, mesmo em um período no qual a construção predial se recuperou e alcançou altas taxas de crescimento no país, diante do processo de interiorização da urbanização a demanda por imóveis deve ter sido relevante nas duas primeiras classes de tamanho de municípios. Os dados comprovam essa assertiva, as variações foram significativamente positivas: $43,2 \%$ e $40,8 \%$, respectivamente.
} 
maior do que nas classes de tamanho subsequentes ( $33,3 \%$ e $31,3 \% ; 27,8 \%$ e $26,5 \%$ ). E isso representava em 2010 o quantum de 22.759 .093 pessoas ocupadas com 15 ou mais anos de idade.

Há, portanto, correlações entre a desconcentração econômica e demográfica e a expansão do terciário em municípios onde o processo de urbanização vem se intensificando no período 2000/2010. Resta examinar melhor a composição intrasetorial e a renda do trabalho, notadamente no comércio e serviços.

O detalhamento da estratificação aqui estudada por meio dos dados da Tabela 3, agora incluindo as atividades "mal definidas" 7, ratifica conclusões anteriormente expostas: o incremento de pessoal ocupado entre os dois últimos censos foi da seguinte magnitude: 24,0\% entre os municípios até 50 mil habitantes; 39,3\% entre os municípios de 50 a 500 mil habitantes; $36,8 \%$ na classe 500 a 1000.000 de habitantes; e $31,8 \%$ no grupo que reúne os municípios com mais de um milhão de habitantes.

As atividades comerciais, mais especificamente, experimentaram um forte incremento no período, notadamente entre os municípios de pequeno tamanho e os municípios das cidades de porte médio (47,8\%). Nas demais classes de tamanho o setor cresceu em níveis próximos de $30 \%$.

No interior do terciário foi, sem dúvida, o setor de serviços (desagregado em quatro categorias na Tabela 3) o que ocupou maior número de pessoas em todas as classes de tamanho de cidades, notadamente no grupo que inclui as grandes e médias cidades. A variação relativa da ocupação em atividades de serviços foi maior no grupo de municípios que inclui os municípios 50 a 500 mil habitantes $(34,8 \%)$, secundado pela classe de municípios com tamanhos entre 500 e 1,0 milhão de habitantes. A menor variação $(25,8 \%)$ nos grandes municípios explica-se pelo fato de que, historicamente, as cidades desses municípios já possuem muito mais estabelecimentos no setor de serviços do que nas classes de menor tamanho. Contudo, ressalte-se que entre 2000 e 2010 o setor evoluiu de 8.837.521 ocupados para 11.119 .433 no rol dos grandes municípios, números só

\footnotetext{
7 As atividades "mal definidas" tiveram um aumento explosivo entre 2000 e 2010, o que pode indicar o surgimento de novas ocupações de difícil definição de acordo com as existentes no Código Brasileiro de Ocupações.
} 
ultrapassados pelos registrados no grupo de municípios de 50 a 500 mil (10.791.012 ocupados em 2000 e 14.549.685 em 2010).

Como anteriormente assinalado, a interiorização da urbanização resultou na expansão das atividades comerciais e de serviços, conviria, no entanto indagar sobre o tipo de serviços que se expande na rede de localidades, afinal, para alguns analistas a entrada de cerca de 40 milhões de indivíduos na classe média é reflexo da ocupação em atividades pior remuneradas e de baixa qualificação. Isso explicaria porque essa "nova" classe média gasta tudo que ganha: uma característica marcante das classes populares trabalhadoras, que ao elevar o rendimento ampliam imediatamente o padrão de consumo (Pochmann, 2012, p. 10). Ao não possuir rendimentos suficientes para a compra de ativos e constituição de poupança, pulveriza seus ganhos no consumo de bens não essenciais. Essas evidências são observadas nos dados aqui examinados? Se frações da classe média emergiram economicamente entre 2000 e 2010 isso pode ser comprovado pela estratificação em classes de tamanho?

Os dados aqui organizados não corroboram essas assertivas. Os serviços "produtivos" e os intitulados "social e administração pública" ${ }^{8}$, os que requisitam pessoal mais qualificado, são os que mais se expandiram no período (maior variação relativa), sobretudo entre os municípios que sediam cidades intermediárias, apesar de o grupo dos ocupados nos "serviços pessoais" ter se incrementado também em todas as classes de tamanho. Esmiuçando essa conclusão e dando expressão aos números absolutos pode-se dizer que, de fato, o crescimento das atividades pior remuneradas e de menor qualificação sediadas nos "serviços pessoais" foi particularmente notável nos municípios intermediários (variação de $25,6 \%)$ e no rol dos com população entre 500 e 1,0 milhão de habitantes $(23,7 \%)$, o que, respectivamente, significou 5.077.156 e 1.331.917 de ocupados em 2010 (ver Tabela 3). Aqui os céticos poderão arguir: esses números são muito maiores que os discriminados nos serviços de maior qualificação. Novamente as inferências empíricas não dão força a essa afirmativa. Se, de fato, os números dos ocupados nos "serviços produtivos" (os que mais se expandiram, chegando a 48,8\% nos municípios intermediários) são bem menores que os dos serviços pessoais (da ordem de 2,4 milhões nos municípios intermediários) os números do

\footnotetext{
${ }^{8}$ A subdivisão do setor de serviços aqui adotada foi adaptada de IPEAD (2014) e Cedeplar (2004).
} 
pessoal ocupado nos "serviços sociais e da administração pública" são de outra ordem de grandeza: em 2010 foram 3.779.210 nos pequenos municípios; 5.077.156 ocupados nos municípios médios; 1.331.917 na classe subsequente; e 3.712 .979 no rol dos maiores municípios. Nesse universo há muitos trabalhadores que não possuem alto nível de instrução ${ }^{9}$ e de qualificação, mas foi significativo o incremento dos ocupados entre 2000 e 2010 (39,4\% no rol dos intermediários) e deve ser muito alta a proporção dos que fizeram concurso público nas três esferas do poder publico (federal, estadual e municipal). Enfim, a ação direta do Estado sobre o mercado de trabalho continua sendo muito relevante. Entre os dois últimos censos os "serviços sociais e da administração" cresceram à taxa de 2,9\% a.a., muito superior ao crescimento demográfico do país, e incidiu principalmente na classe de municípios de porte médio.

Tabela 3 - Total de ocupados com 15 ou mais anos de idade por setor de atividade e porte populacional do município de residência em 2000 e 2010

\begin{tabular}{|c|c|c|c|c|c|}
\hline \multicolumn{2}{|c|}{$\begin{array}{c}\text { Classe de Tamanho } \\
\text { dos Municípios e } \\
\text { Variação }\end{array}$} & $\begin{array}{c}\text { Agro- } \\
\text { pecuário }\end{array}$ & $\begin{array}{c}\text { Indústria de } \\
\text { Transformação/E } \\
\text { xtração }\end{array}$ & $\begin{array}{c}\text { Construção } \\
\text { Civil }\end{array}$ & Comércio \\
\hline \multirow{3}{*}{$\begin{array}{l}50 \text { mil } \\
\text { ou } \\
\text { menos }\end{array}$} & 2.000 & 8.906 .178 & 2.322 .029 & 1.239 .914 & 2.060 .264 \\
\hline & 2.010 & 8.931 .638 & 3.024 .376 & 1.775 .437 & 3.115.372 \\
\hline & Var.\% & 0,3 & 30,2 & 43,2 & 51,2 \\
\hline \multirow{3}{*}{$\begin{array}{c}50 \text { a } 500 \\
\text { mil }\end{array}$} & 2.000 & 2.403 .992 & 3.832 .527 & 1.931 .892 & 3.714 .336 \\
\hline & 2.010 & 2.582 .497 & 4.687 .066 & 2.719 .490 & 5.489 .918 \\
\hline & Var.\% & 7,4 & 22,3 & 40,8 & 47,8 \\
\hline \multirow{3}{*}{$\begin{array}{l}500 \text { mil } \\
\text { a } 1 \\
\text { milhão }\end{array}$} & 2.000 & 108.242 & 833.722 & 428.026 & 972.844 \\
\hline & 2.010 & 124.232 & 905.498 & 570.519 & 1.329 .734 \\
\hline & Var.\% & 14,8 & 8,6 & 33,3 & 36,7 \\
\hline \multirow{3}{*}{$\begin{array}{l}1 \text { milhão } \\
\text { ou mais }\end{array}$} & 2.000 & 108.562 & 1.908 .873 & 943.942 & 2.534 .601 \\
\hline & 2.010 & 137.575 & 1.918 .383 & 1.206 .058 & 3.272 .705 \\
\hline & Var.\% & 26,7 & 0,5 & 27,8 & 29,1 \\
\hline
\end{tabular}

${ }^{9}$ Dados não apresentados nesse estudo mostram ter havido ente 2000 e 2010 um aumento significativo de trabalhadores de maior nível de escolaridade em todas as classes de tamanho de municípios, em especial os com Ensino Médio e Superior nos municípios de pequeno e médio porte. 


\begin{tabular}{|c|c|c|c|c|c|c|c|}
\hline \multirow{2}{*}{\multicolumn{2}{|c|}{$\begin{array}{c}\text { Classe de Tamanho } \\
\text { dos Municípios e } \\
\text { Variação }\end{array}$}} & \multicolumn{4}{|c|}{ Serviços } & \multirow{2}{*}{$\begin{array}{c}\text { Mal } \\
\text { definidas }\end{array}$} & \multirow[t]{2}{*}{ TOTAL } \\
\hline & & \multirow{2}{*}{\begin{tabular}{r|} 
Produtivo \\
603.812
\end{tabular}} & \multirow{2}{*}{$\begin{array}{r}\text { Distributivo } \\
640.744\end{array}$} & Pessoal & \multirow{2}{*}{\begin{tabular}{|c|c|}
$\begin{array}{c}\text { Social/Adm } \\
\text { Pública }\end{array}$ \\
2.854 .046
\end{tabular}} & & \\
\hline $50 \mathrm{mil}$ & 2.000 & & & 2.722 .716 & & 205.879 & 21.555 .581 \\
\hline ou & 2.010 & 905.115 & 790.140 & 3.277 .551 & 3.779 .210 & 1.121 .682 & 26.720 .520 \\
\hline & Var.\% & 49,9 & 23,3 & 20,4 & 32,4 & 444,8 & 24,0 \\
\hline \multirow{3}{*}{$\begin{array}{c}50 \text { a } 500 \\
\text { mil }\end{array}$} & 2.000 & 1.641 .592 & 1.142 .951 & 4.365 .100 & 3.641 .369 & 310.546 & 22.984.304 \\
\hline & 2.010 & 2.443 .203 & 1.548 .169 & 5.481 .158 & 5.077 .156 & 1.980 .416 & 32.009 .072 \\
\hline & Var.\% & 48,8 & 35,5 & 25,6 & 39,4 & 537,7 & 39,3 \\
\hline \multirow{3}{*}{$\begin{array}{c}500 \text { mil } \\
\text { a } 1 \\
\text { milhão }\end{array}$} & 2.000 & 537.842 & 298.242 & 1.109 .396 & 1.017 .449 & 61.163 & 5.366 .926 \\
\hline & 2.010 & 783.515 & 372.015 & 1.372 .011 & 1.331 .917 & 553.222 & 7.342 .662 \\
\hline & Var.\% & 45,7 & 24,7 & 23,7 & 30,9 & 804,5 & 36,8 \\
\hline \multirow{3}{*}{$\begin{array}{l}1 \text { milhão } \\
\text { ou mais }\end{array}$} & 2.000 & 2.068 .870 & 829.180 & 2.982.391 & 2.957 .083 & 247.140 & 14.580 .642 \\
\hline & 2.010 & 2.871 .346 & 1.002 .802 & 3.532 .305 & 3.712 .979 & 1.558 .007 & 19.212 .160 \\
\hline & Var.\% & 38,8 & 20,9 & 18,4 & 25,6 & 530,4 & 31,8 \\
\hline
\end{tabular}

Fonte: IBGE, Censos Demográficos - Dados trabalhados pelos autores

E o que dizer da renda dos ocupados entre 2000 e 2010? Apesar das dificuldades de obtenção de dados fidedignos sobre renda para todos os municípios brasileiros é possível fazer algumas inferências aproximadas com base nos dados censitários. Para tanto, a organização em sequencia estratifica a renda auferida no trabalho principal dos ocupados com 15 ou mais anos de idade e a renda mediana foi utilizada como medida de tendência central.

Procurando focalizar principalmente as atividades instaladas em áreas urbanas, as conclusões retiradas do exame da Tabela 4 podem ser sumarizadas como se segue: a) os aumentos da renda mediana ${ }^{10}$ contemplaram uma ampla gama de setores de atividades

\footnotetext{
${ }^{10}$ Os números inteiros da mediana em 2010 e fracionados em 2000 foram revisados e estão corretos. O que explica os valores exatos em 2010 é a preferência por números inteiros nas respostas ao recenseador. Como é alto o numero de respondentes que declaram a renda como um número redondo ( 2 mil, 3 mil ...), torna-se alta a probabilidade de a mediana "cair" em um número redondo. Probabilidade ampliada na medida em que o artigo utiliza a informação da renda no trabalho principal, apurada em uma única pergunta. Não se trata, portanto, do somatório de rendimentos declarados em vários quesitos sobre renda e subsequente divisão por um número de pessoas (renda per capita, renda média). Quanto aos valores quebrados de 2000 a explicação é a seguinte: todos os valores de 2000 foram multiplicados pelo deflator do INPC acumulado entre 2000 e 2010, número equivalente a 1,9645958. É a multiplicação pelo deflator que transforma os números inteiros em fracionados. Por exemplo: sem a correção pelo INPC os valores medianos das rendas auferidas no trabalho principal para o grupo com ensino superior completo por Classe de Tamanho de municípios eram, respectivamente, $\mathrm{R} \$ 894,00, \mathrm{R} \$ 1.200,00, \mathrm{R} \$ 1300,00$ e $\mathrm{R} \$ 1800,00$.
} 
entre 2000 e 2010 (com variações relativas de dois dígitos), e as remunerações mais altas concentraram-se nos serviços "social e da administração pública", sucedidas pelos ganhos dos ocupados nos "serviços produtivos" (o que se ajusta às análises anteriores sobre trabalhadores mais qualificados); b) Entre os menos qualificados, as remunerações são bem menores, mas ainda assim expressam incrementos significativos no período, notadamente no grupo dos "serviços pessoais" entre os pequenos municípios e cidades médias; c) focalizando as grandes cidades e as cidades médias, os diferenciais de remuneração não são muito significativos: são idênticas as medianas da renda do pessoal ocupado na indústria, na construção civil e nos serviços distributivos. Nas maiores cidades a renda mediana é superior entre os ocupados no comércio, nos serviços "produtivo", "pessoais" e "sociais e da administração pública". Contudo, é principalmente na classe de municípios de maior tamanho que se verificou os menores aumentos de remuneração, com variações relativas inferiores a um dígito na indústria, construção civil, comércio e serviços (nos serviços distributivos a variação chegou a ser negativa, $-5,7 \%$ !). Por outro lado, em ocupações nas quais os diferenciais a favor das grandes cidades foi maior, os ganhos monetários devem ter se dissolvido nos crescentes custos de deslocamento que as grandes metrópoles impõem aos trabalhadores na atualidade. ${ }^{11}$

\footnotetext{
${ }^{11}$ No Brasil, após a onda de protestos de junho de 2013, a urbanista Ermínia Maricato escreveu um artigo com o provocativo e sugestivo título "É a questão urbana, estúpido!". Nele, a autora indica os grandes problemas que atingem as maiores cidades do país e observa que melhores salários não asseguram melhoria nas condições de vida ou redução das disparidades na distribuição de renda. Isso porque as condições de vida são superiores se houver políticas públicas urbanas eficazes nas áreas de transporte, saneamento, moradia, saúde, educação, segurança, lazer, coleta de lixo. Na verdade a cidade representa um grande patrimônio material construído, mas sua apropriação é desigual e comumente as rendas imobiliárias e de localização explicam boa parte das desigualdades socioespaciais existentes. (Maricato, 2013, p. 6)
} 
Tabela 4 - Renda mediana (em reais) dos ocupados com 15 ou mais anos de idade no trabalho principal por setor de atividade e porte populacional do município de residência em 2000 e 2010

\begin{tabular}{|c|c|c|c|c|c|}
\hline \multicolumn{2}{|c|}{$\begin{array}{c}\text { Classe de Tamanho } \\
\text { dos Municípios e } \\
\text { Variação }\end{array}$} & Agropecuário & $\begin{array}{c}\text { Indústria de } \\
\text { Transformação/E } \\
\text { xtração } \\
\end{array}$ & $\begin{array}{l}\text { Construção } \\
\text { Civil }\end{array}$ & Comércio \\
\hline \multirow{3}{*}{$\begin{array}{l}50 \text { mil } \\
\text { ou } \\
\text { menos }\end{array}$} & 2.000 & 196,46 & 491,15 & 510,79 & 491,15 \\
\hline & 2.010 & 200,00 & 670,00 & 600,00 & 540,00 \\
\hline & Var.\% & 1,8 & 36,4 & 17,5 & 9,9 \\
\hline \multirow{3}{*}{$\begin{array}{c}50 \text { a } 500 \\
\text { mil }\end{array}$} & 2.000 & 294,69 & 687,61 & 593,31 & 593,31 \\
\hline & 2.010 & 300,00 & 800,00 & 755,00 & 700,00 \\
\hline & Var.\% & 1,8 & 16,3 & 27,3 & 18,0 \\
\hline \multirow{3}{*}{$\begin{array}{l}500 \text { mil } \\
\text { a } 1 \\
\text { milhão }\end{array}$} & 2.000 & 353,63 & 785,84 & 628,67 & 687,61 \\
\hline & 2.010 & 510,00 & 900,00 & 800,00 & 700,00 \\
\hline & Var.\% & 44,2 & 14,5 & 27,3 & 1,8 \\
\hline \multirow{3}{*}{$\begin{array}{l}1 \text { milhão } \\
\text { ou mais }\end{array}$} & 2.000 & 442,03 & 825,13 & 785,84 & 785,84 \\
\hline & 2.010 & 510,00 & 900,00 & 800,00 & 800,00 \\
\hline & Var.\% & 15,4 & 9,1 & 1,8 & 1,8 \\
\hline
\end{tabular}

\begin{tabular}{|c|c|c|c|c|c|c|}
\hline \multirow{2}{*}{\multicolumn{2}{|c|}{$\begin{array}{l}\text { Classe de Tamanho dos } \\
\text { Municípios e Variação }\end{array}$}} & \multicolumn{4}{|c|}{ Serviços } & \multirow{2}{*}{$\begin{array}{c}\text { Mal } \\
\text { definidas }\end{array}$} \\
\hline & & \multirow{2}{*}{$\begin{array}{r}\text { Produtivo } \\
628,67\end{array}$} & Distributivo & Pessoal & $\begin{array}{l}\text { Social/Adm } \\
\text { Pública }\end{array}$ & \\
\hline \multirow{3}{*}{$\begin{array}{c}50 \text { mil } \\
\text { ou } \\
\text { menos }\end{array}$} & 2.000 & & 746,55 & 296,65 & 528,48 & 392,92 \\
\hline & 2.010 & 800,00 & 800,00 & 500,00 & 700,00 & 510,00 \\
\hline & Var.\% & 27,3 & 7,2 & 68,5 & 32,5 & 29,8 \\
\hline \multirow{3}{*}{$\begin{array}{c}50 \text { a } 500 \\
\text { mil }\end{array}$} & 2.000 & 884,07 & 903,71 & 392,92 & 785,84 & 589,38 \\
\hline & 2.010 & $1.000,00$ & $1.000,00$ & 510,00 & $1.000,00$ & 700,00 \\
\hline & Var.\% & 13,1 & 10,7 & 29,8 & 27,3 & 18,8 \\
\hline \multirow{3}{*}{$\begin{array}{l}500 \text { mil } \\
\text { a } 1 \\
\text { milhão }\end{array}$} & 2.000 & 943,01 & 982,30 & 444,00 & 982,30 & 609,02 \\
\hline & 2.010 & $1.000,00$ & $1.000,00$ & 510,00 & $1.100,00$ & 800,00 \\
\hline & Var.\% & 6,0 & 1,8 & 14,9 & 12,0 & 31,4 \\
\hline \multirow{3}{*}{$\begin{array}{l}1 \text { milhão } \\
\text { ou mais }\end{array}$} & 2.000 & $1.178,76$ & $1.060,88$ & 589,38 & $1.375,22$ & 884,07 \\
\hline & 2.010 & $1.400,00$ & $1.000,00$ & 600,00 & $1.500,00$ & 900,00 \\
\hline & Var.\% & 18,8 & $-5,7$ & 1,8 & 9,1 & 1,8 \\
\hline
\end{tabular}

Fonte: IBGE, Censos Demográficos - Dados trabalhados pelos autores

\subsection{Retratos das diferenças espaciais cotejadas pelo emprego e renda do trabalho}

Diante do exposto caberia averiguar onde foi maior a expansão do emprego no país entre 2000 e 2010, preferentemente particularizando o total de empregos do terciário (marca de urbanização acelerada), e finalmente, como se configuram as desigualdades de renda proveniente do trabalho nas quatro classes de tamanho de municípios aqui discriminadas. 
O mapa em sequência deixa evidente que o crescimento do terciário nas 15 principais metrópoles do país foi relativamente modesto se comparado às demais cidades dos municípios com mais de 50 mil habitantes. As evidências indicam pelo menos três tendências. A primeira, visualmente muito clara, diz respeito à expressiva expansão do terciário de uma miríade de áreas urbanas que fazem parte das grandes periferias das principais metrópoles brasileiras. A região sudeste é particularmente notável pela presença das metrópoles de São Paulo, Rio de Janeiro e Belo Horizonte. A segunda evidência refere-se à expansão da urbanização no "grande oeste" do Brasil atual. São muitas as sedes de municípios nas franjas do arco da pré-Amazônia, no cinturão do agronegócio que, se de um lado ocupa imensas áreas de cerrado do Centro Oeste-Norte, também viabiliza a forte expansão de um conjunto expressivo de cidades de porte médio. A terceira conclusão derivada da observação do cartograma diz respeito à urbanização em uma área antiga do interior da região Nordeste, mas que exibe na atualidade significativa expansão do emprego no comércio e serviços.

Figura 1: Variação percentual da população de 15 anos ou mais de idade empregada nas atividades do setor terciário - 2000/2010

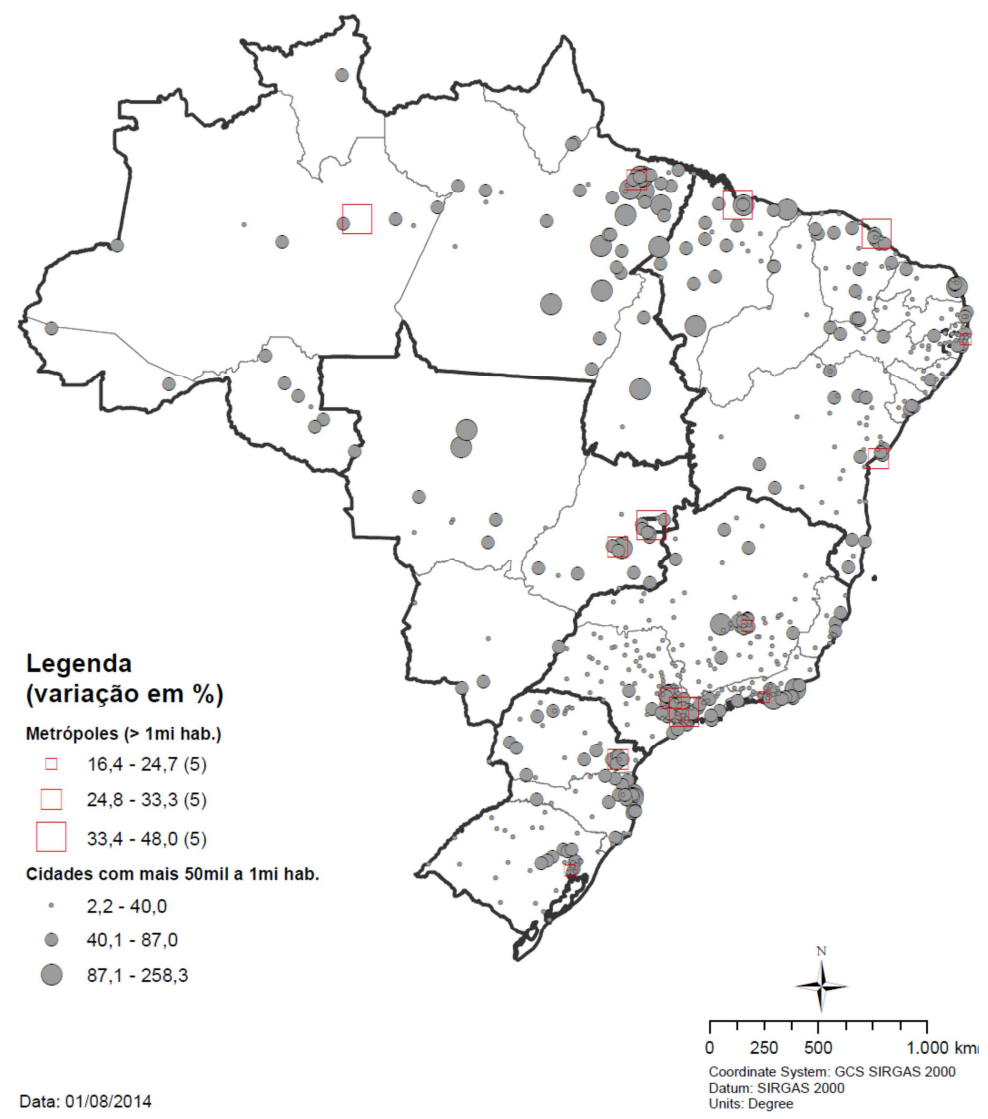

Fonte: IBGE, Censos Demográficos - Dados trabalhados pelos autores 
Diante dessas evidências resta averiguar os diferenciais de desigualdade socioespacial, ou seja, no interior das discussões sobre mudanças no mercado de trabalho na rede de cidades há um ponto que merece atenção: os rendimentos do trabalho são muito desiguais e extremamente variáveis conforme o tamanho das localidades?

Retomando a mesma metodologia de exploração dos dados do censo conviria examinar os dados de rendimento de 2000 e 2010 com mais detalhe. Uma forma de se fazer isso é associar a representação da rede de cidades por classe de tamanho de municípios com as pirâmides de renda conforme mostra a Coleção de Gráficos 1. Aqui o que se procura é visualizar a distribuição de renda derivada do trabalho principal ${ }^{12}$ da população com 15 anos ou mais de idade por sexo. Os dados graficados permitem retirar as seguintes conclusões gerais e específicas:

i) - ao lado do aumento de pessoas ocupadas em cada faixa de rendimento houve um incremento da renda do trabalho entre 2000 e 2010 em todas as Classes de Tamanho de municípios nas faixas de renda que chegam até 10 salários mínimos (s.m.);

ii) - esse incremento é mais expressivo na faixa de renda de 1 a 2 salários mínimos. Acima de três s.m. os números absolutos declinam significativamente;

iii) - no grande conjunto de pequenos municípios (até 50 mil habitantes) os dados indicam que os trabalhadores auferem rendas mais baixas que em todas as demais Classes de Tamanho. Isso não causa surpresa ao se observar que esses municípios reúnem uma grande quantidade de ocupações não qualificadas nas atividades agrícolas tradicionais;

iv) - a Classe que agrega os municípios de porte médio se destaca frente às demais ao exibir o maior contingente de pessoas na faixa de renda de 2 a 3 s.m. É provável que boa parte desses trabalhadores tenha melhorado seu nível de renda no período ainda que estejam localizados na base da pirâmide de renda (provavelmente muitos deles auferiam no ano 2000 menos de dois salários mínimos);

\footnotetext{
${ }^{12}$ Adicionalmente, uma conclusão deve ser assinalada: a diferença entre as taxas de crescimento da renda total e da renda do trabalho principal nas grandes cidades é grande (3,5\% contra $2,7 \%)$. Dados aqui não apresentados mostram, para a população de 15 anos ou mais empregada nas metrópoles, um declínio da participação relativa do rendimento do trabalho principal na renda total entre 2000 e 2010, de $89 \%$ para $82 \%$. Isso deve se explicar pela ampliação da participação dos rendimentos originários de outras fontes, como heranças, ganhos financeiros, alugueis, etc.
} 
v) - o exame da composição da renda por sexo traz à luz duas evidências marcantes: a quantidade de mulheres inseridas no mercado de trabalho aumenta significativamente em termos proporcionais à medida que cresce o tamanho do município de residência, embora em todos os casos a presença numérica dos homens Ihe seja superior. Nas faixas de maior remuneração o número de homens é, em todos os casos, bastante superior ao das mulheres. De forma semelhante ao já observado, no rol das cidades médias aumentou muito a presença de mulheres trabalhadoras na faixa de renda de 2 a 3 salários mínimos. Esse dado constitui um indicador de redinamização do mercado de trabalho no Brasil.

Coleção de Gráficos 1: Distribuição da população ocupada com 15 anos ou mais de idade segundo faixa de rendimento no trabalho Principal (em salários mínimos) por sexo e classe de tamanho populacional dos municípios em 2010 (em 1.000 habitantes).

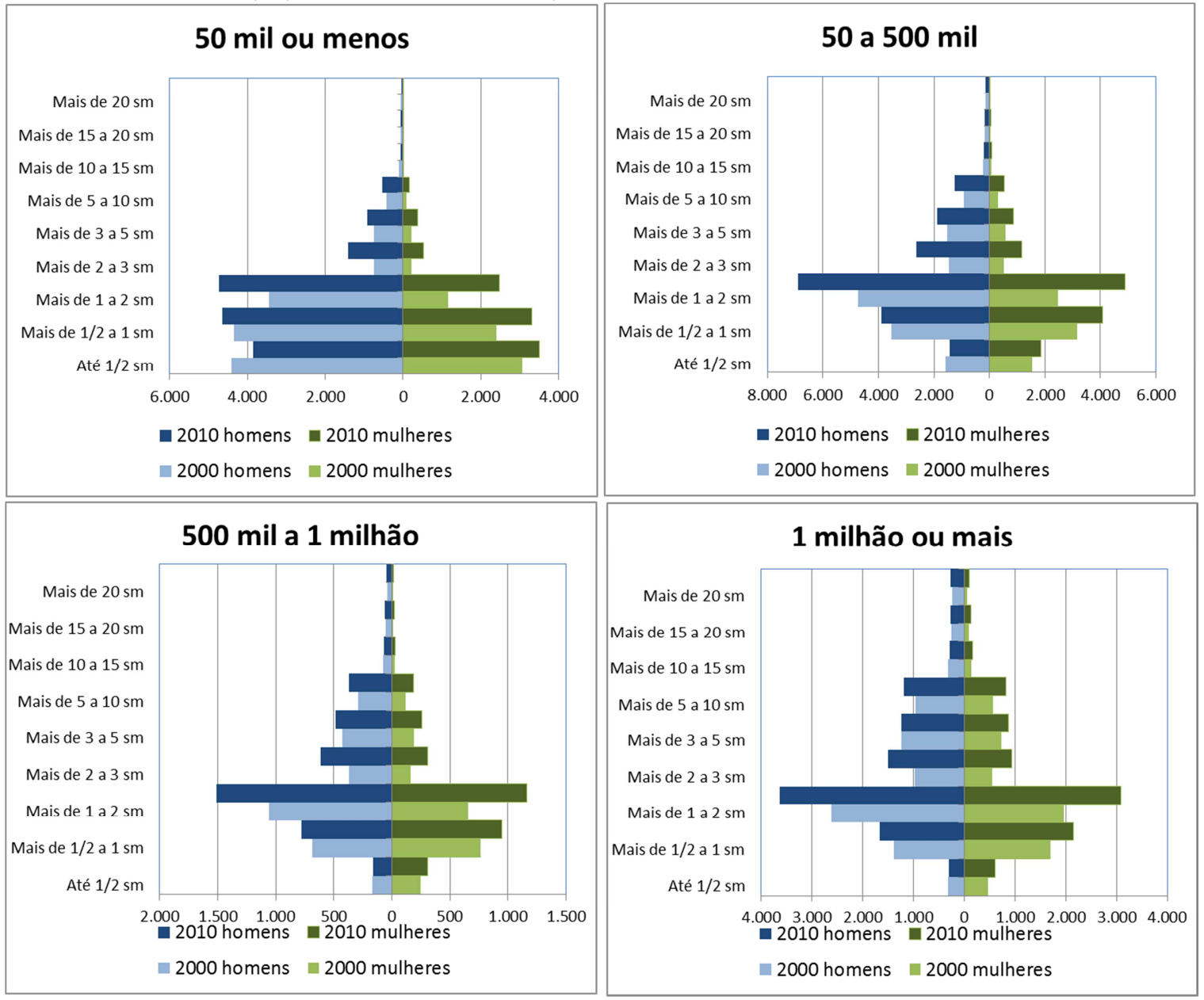

Fonte: IBGE, Censos Demográficos - Dados trabalhados pelos autores 


\section{Conclusões}

Algumas das conclusões mais importantes desse trabalho são as seguintes: a) houve melhora generalizada nos rendimentos entre 2000 e 2010 e as mulheres, mais numerosas nas maiores cidades, melhoraram suas rendas. A feminização de parte do mercado de trabalho nas grandes cidades se faz evidente; b) é grande a distância de nossas pirâmides com os conhecidos "losangos" dos países desenvolvidos. Os dados indicam dois pontos de discrepância nos desenhos dos gráficos de barra. O primeiro refere-se ao "fosso" que separa os remunerados de 1 a 2 s.m. dos remunerados com 2 a 3 s.m. O segundo diz respeito à distância que separa os que ganham mais ou menos de 10 s.m. Os municípios com mais de um milhão de habitantes do Brasil conformam a Classe de Tamanho com o mercado de trabalho mais desigual. Nestes, 59,5\% da população empregada de 15 anos ou mais recebe até 2 s.m. e participa com apenas $20 \%$ da renda auferida no trabalho principal, enquanto $6,4 \%$ recebe 10 ou mais s.m e abarca $37,7 \%$ dos rendimentos.

O Brasil experimentou, de fato, um importante incremento da renda do trabalho entre 2000 e 2010, mas paradoxalmente a desigualdade é ou continua marcante nas grandes cidades, embora só nelas existam mulheres visíveis nas faixas de alta renda.

No interior das atividades industriais instaladas no Brasil do início do século XXI há indicações de clara expansão do emprego a despeito de haver incrementos de produtividade em alguns setores e redução relativa do estoque de empregos. Uma desindustrialização, entretanto não tipifica a situação brasileira. Destarte, a agricultura comercial e o agronegócio, o avanço recente da indústria de extração mineral e de transformação em uma miríade de pequenos municípios, além do formidável incremento da construção civil devem ter impulsionado vigorosamente o terciário urbano na rede de cidades como os dados demonstraram. Uma fração significativa da população beneficiada com a expansão do emprego no setor de serviços deve integrar segmentos intermediários formadores da chamada nova classe média. Residem nos interstícios derivados da interiorização da urbanização brasileira, fora das metrópoles.

O volume de empregos e o rendimento do trabalho relativamente alto entre os protagonistas da interiorização da urbanização, particularmente as cidades de porte médio, sinalizam para mudanças na estrutura espacial do emprego; para um novo padrão de 
distribuição do emprego e renda que pode estar desencadeando alterações estruturais sensíveis na inserção ocupacional no Brasil.

As mudanças são significativas, a expansão da renda e do emprego foram notáveis, embora os empregos sediados na indústria moderna foram e estão sendo no momento bem inferiores aos do alto e baixo terciários, o que, a longo prazo, poderá comprometer a própria expansão dos setor de serviços e a interiorização da urbanização, uma vez que a agroindústria não tem envergadura para suprir a demanda futura de empregos, futuro que seria muito pior se não houvesse o declínio tendencial do volume da população em idade ativa.

A elasticidade dos investimentos industriais foi $e$ continua sendo essencial ao desenvolvimento e os gargalos do setor e sua redução de competitividade são desafios que fazem parte da agenda política do Brasil atual. Inovação tecnológica implica ganhos de produtividade e novos impactos no mercado de trabalho. Se isso amedronta os políticos profissionais, convém pensar nos requerimentos de qualquer capitalismo que se pretende competitivo internacionalmente.

\section{Referências}

Cano, W. Ensaios sobre a crise urbana do Brasil. Editora Unicamp. Campinas. 2011

CEDEPLAR - Centro de Desenvolvimento e Planejamento Regional. Projeto Belo Horizonte no Século XXI. Relatório do MÓDULO 4 - Serviços e a rede urbana metropolitana. Belo Horizonte, 20 de julho de 2004, disponível em http://web.cedeplar.ufmg.br/cedeplar/site/pesquisas/pbh/arquivos/mod4.pdf, acessado em 16 de maio de 2014.

Ferreira, R. N.; Matos, R. E. S. Dinamismo do mercado de trabalho formal e mobilidade espacial de trabalhadores. In: MATOS, Ralfo; SOARES, Weber. (Org.). Desigualdades socioespaciais, redes e espacialidades emergentes no Brasil. 1 ed. Rio de Janeiro: Garamond, 2010, v. 1, p. 137-162.

Ferreira, R. N.; Matos, R. E. S. “A dinâmica do emprego formal no Brasil da década de 1990 e as tendências de reestruturação territorial”. In: XI Encontro Nacional da Associação Nacional de Pós-graduação e Pesquisa em Planejamento Urbano e Regional - ANPUR, 2005, Salvador-BA. Anais... Salvador: ANPUR, 2005.

IPEAD - Fundação Instituto de Pesquisas Econômicas, Administrativas e Contábeis de Minas Gerais. Desenvolvimento de metodologia e cálculo de indicadores socioeconômicos de Belo Horizonte (Relatórios 10,11,12). Disponível em: http://portalpbh.pbh.gov.br/pbh/ecp/files.do?evento=download\&urlArqPIc=Indicadores_Socioeconomicos_de _Belo_Horizonte.pdf, acessado em 16 de maio de 2014.

Kaldor, N. Causes of the slow rate of economic growth in the United Kingdom. Cambridge University Press, 1966.

Maricato, E. “É a questão urbana, estúpido!". Le Monde Diplomatique Brasil, ano 7, n. 73, p. 6-7, agosto de 2013. 
Matos, R. E. S. "Aglomerações urbanas, rede de cidades e desconcentração demográfica no Brasil”. In: $\underline{X}$ Encontro Nacional de Estudos Populacionais, 2000, Caxambu-MG. Anais...Belo Horizonte: ABEP, 2000.

Matos, R.; Braga, F. “Rede Urbana e redistribuição espacial da população brasileira”. In: XIII Encontro Nacional de Estudos Populacionais, 2002, Ouro Preto-MG. Anais... Ouro Preto: ABEP, 2002.

Matos, R.; Ferreira, R. N.. "Inserção ocupacional de emigrantes das Áreas Metropolitanas de São Paulo e Rio de Janeiro". Revista Brasileira de Estudos da População, Campinas, v. 21, p. 83-100, 2004.

Matos, R.; Ferreira, R. N. "De qual centro e periferia estamos falando? Evidências acerca de "mobilidades" da força de trabalho e condições de vida em regiões metropolitanas selecionadas". In XV Encontro Nacional da ANPUR, 2013, Recife-PE. Anais... Recife: ANPUR, 2013.

Matos, R.; Ferreira, R. N.; Garcia, R. A.. "Padrão de vida, qualidade de vida e status migratório na rede de cidades do Brasil atual". In: VIII Encontro Nacional sobre Migrações, 2013, Belo Horizonte. Anais ... Belo Horizonte: ABEP, 2013.

Pochmann, M. Nova Classe Média? O trabalho na base da pirâmide social brasileira. São Paulo. Boitempo Editorial. 2012.

Squeff, G. C. "Desindustrialização: luzes e sombras no debate brasileiro". Texto para discussão 1747. IPEA. Brasilia, 2012 